\title{
A Study on the Damping Capacities of Mg-Zn-Y-Based Alloys with Lamellar Long Period Stacking Ordered Phases by Preparation Process
}

\author{
Ruopeng Lu (D, Kai Jiao, Yuhong Zhao *, Kun Li, Keyu Yao and Hua Hou \\ College of Materials Science and Engineering, North University of China, Taiyuan 030051, China; \\ lurpzbdx@nuc.edu.cn (R.L.); jiaokai0608@hotmail.com (K.J.); likun1027@hotmail.com (K.L.); \\ qmnmna@outlook.com (K.Y.); houhua@nuc.edu.cn (H.H.) \\ * Correspondence: zhaoyuhong@nuc.edu.cn; Tel.: +86-150-3517-2958
}

Citation: Lu, R.; Jiao, K.; Zhao, Y.; Li, K.; Yao, K.; Hou, H. A Study on the Damping Capacities of

Mg-Zn-Y-Based Alloys with Lamellar Long Period Stacking Ordered Phases by Preparation Process. Metals 2021, 11, 79. https://doi.org/10.3390/met11010079

Received: 3 November 2020 Accepted: 23 December 2020 Published: 2 January 2021

Publisher's Note: MDPI stays neutral with regard to jurisdictional clai$\mathrm{ms}$ in published maps and institutional affiliations.

Copyright: $(2021$ by the authors. Licensee MDPI, Basel, Switzerland. This article is an open access article distributed under the terms and conditions of the Creative Commons Attribution (CC BY) license (https:// creativecommons.org/licenses/by/ $4.0 /)$.

\begin{abstract}
Mg}$ alloys with fine mechanical properties and high damping capacities are essential in engineering applications. In this work, $\mathrm{Mg}-\mathrm{Zn}-\mathrm{Y}$ based alloys with lamellar long period stacking ordered (LPSO) phases were obtained by different processes. The results show that a more lamellar second phase can be obtained in the samples with more solid solution atoms. The density of the lamellar LPSO phase has an obvious effect on the damping of the magnesium alloy. The compact LPSO phase is not conducive to dislocation damping, but sparse lamellar phases can improve the damping capacity without significantly reducing the mechanical properties. The $\mathrm{Mg}_{95.3} \mathrm{Zn}_{2} \mathrm{Y}_{2.7}$ alloy with lamellar LPSO phases and $\sim 100 \mu \mathrm{m}$ grain size exhibited a fine damping property of 0.110 at $\varepsilon=10^{-3}$.
\end{abstract}

Keywords: Mg alloys; damping property; LPSO phases; mechanical property

\section{Introduction}

Damping performance refers to the reduction of unwanted vibrations in the structure without external dampers [1]. Mg alloys have the best damping capacities in a wide variety of metal materials, so there is a need for the development of a high damping magnesium alloy that meets the needs of modern industry for vibration reduction [2]. However, in order to obtain high damping properties, magnesium alloys are usually at the expense of mechanical properties. Several techniques have been applied to improve the mechanics and damping of magnesium alloys such as heat treatment, alloying, and deformation processes [3-6]. However, these studies showed that the damping and mechanics of magnesium alloys are difficult to simultaneously improve.

In recent years, the long-period stacking ordering (LPSO) phase in magnesium alloys has been a research hotspot [7-9]. A large number of studies have shown that the LPSO phase can strengthen magnesium alloys $[10,11]$. Wang studied the damping and mechanical properties of magnesium alloys containing the LPSO phase (i.e., $\mathrm{Mg}-\mathrm{Zn}-\mathrm{Y}-\mathrm{Zr}$ [12], Mg$\mathrm{Cu}-\mathrm{Mn}-\mathrm{Zn}-\mathrm{Y}$ [13], and Mg-Ni-Y [14] alloys) and it was found that LPSO could not only improve the mechanics, but also the damping performance. Tang et al. [15] studied the mechanical and damping properties of $\mathrm{Mg}-\mathrm{Zn}-\mathrm{Y}-\mathrm{Zr}$ alloys, and found that the LPSO phase in magnesium alloys could be used as a new source of energy dissipation and improve the damping properties of the alloys. This series of studies has shown that magnesium alloys containing LPSO are promising in damping alloys [16].

Heat treatment is usually used to improve the microstructure and properties of $\mathrm{Mg}$ alloys. It can redistribute the dislocation or defect density in materials and improve the damping properties of alloys by eliminating disordered areas [17,18]. González-Martínez et al. [19] explored the diffusion-controlled mechanism in aging treatments and found that it could regulate the hardness and damping performance of $\mathrm{Mg}-\mathrm{Al}-\mathrm{Zn}$ alloys. The effect of 
heat treatment on the magnesium alloy containing the LPSO phase is more significant [20]. Experiments have shown that through different heat treatment processes in $\mathrm{Mg}-\mathrm{Zn}-\mathrm{Y}$ alloys, it is possible to obtain block, lamellar, and rod-like LPSO phases, in which the appearance of the rod-shaped LPSO phases is more conducive to obtaining high damping and high yield strength.

The study on the evolution control of LPSO phase can improve the damping characteristics of the $\mathrm{Mg}$ alloy. Many scholars have conducted research and discussion on the formation and evolution mechanism of the LPSO phase. M. Yamasaki [21] researched the mechanical properties of warm-extruded $\mathrm{Mg}-\mathrm{Zn}-\mathrm{Gd}$ alloy with coherent $14 \mathrm{H}$ long periodic stacking ordered structure precipitate. E. Oñorbe [22] researched the evolution of internal strain in $\mathrm{Mg}-\mathrm{Y}-\mathrm{Zn}$ alloys with a long period stacking ordered structure. Shi [23] researched the role of the LPSO phase in crack propagation behavior of an As-cast $\mathrm{Mg}-\mathrm{Y}-\mathrm{Zn}$ alloy subjected to dynamic loadings. During heat treatment, lamellar LPSO phases are frequently observed in Mg-RE-Zn (RE stands for rare earth elements) alloys [24,25].

However, Mg alloys with lamellar LPSO phases have not been systematically studied in terms of their damping properties. In the present study, we attempted to optimize the damping and mechanical properties of $\mathrm{Mg}-\mathrm{Zn}-\mathrm{Y}$ alloys containing lamellar LPSO phases by changing the melt solidification conditions and heat treatment process. The effects of lamellar LPSO phases on the damping and mechanical properties of the alloy were investigated and discussed.

\section{Materials and Methods}

Lump pure $\mathrm{Mg}$, granular pure $\mathrm{Zn}$, and master alloy with a composition ratio of $\mathrm{Mg}$-30 wt. $\%$ Y obtained by smelting were used to make the $\mathrm{Mg}_{95.3} \mathrm{Zn}_{2} \mathrm{Y}_{2.7}$ alloys. The materials were melted in an electrical furnace under a protective argon atmosphere. Two group samples were made in a thin shell iron crucible under different conditions. One sample was quickly cooled in salt brine with an iron crucible (Sample I); under this process, the alloy liquid was cooled from $973 \mathrm{~K}$ to less than $373 \mathrm{~K}$ in $30 \mathrm{~s}$, and its cooling rate was about $20 \mathrm{~K} / \mathrm{s}$. The other was cooled in air (sample III). The cast alloy was then heated at $673 \mathrm{~K}$ for $10 \mathrm{~h}$, quenched, and these materials were labeled as samples II and IV. Two groups of experimental alloy sample numbers and corresponding status information of each sample are listed in Table 1.

Table 1. Two groups of experimental alloy sample numbers and corresponding status information of each sample.

\begin{tabular}{cccc}
\hline Alloy & Craft & Grain Size/ $\mu$ m & Main Second Phase \\
\hline Sample I & Cast alloy cooling in salt water & $\sim 20$ & Block LPSO phase \\
Sample II & Cast alloy heat treatment at $673 \mathrm{~K} \times 10 \mathrm{~h}+$ cooling in salt water & $\sim 20$ & Block LPSO phase + Dense \\
lamellar LPSO phases \\
Sample III & Cast alloy cooling in air & $\sim 100$ & Block LPSO phase \\
Sample IV & Cast alloy heat treatment at $673 \mathrm{~K} \times 10 \mathrm{~h}+$ cooling in air & $\sim 100$ & Block LPSO phase + Sparse \\
& & & lamellar LPSO phases \\
\hline
\end{tabular}

Microstructural analysis and phase identification were performed using a Vega II LMU scanning electron microscope (SEM, Vega II, Brno, Czech Republic). The ultrastructure of LPSO phases were further investigated using a Zeiss Libra transmission electron microscope 200FE (TEM, Zeiss Libra, Berlin, Germany). A Shimadzu CMT-5105 material testing machine (Shimadzu CMT-5105, Tokyo, Japan) was used to conduct the tensile tests, where the tensile test specimen size was $45 \mathrm{~mm} \times 5 \mathrm{~mm} \times 1.2 \mathrm{~mm}$, and the tensile rate was $3 \mathrm{~mm} / \mathrm{min}$. The dynamic performance analyzer (TA-DMA Q800, Chicago, IL, USA) was used to perform the damping performance test in the single cantilever vibration mode and evaluated using $Q^{-1}=\tan \phi$. Damping test sample size was $45 \mathrm{~mm} \times 5 \mathrm{~mm} \times 1.2 \mathrm{~mm}$. The test temperature was room temperature and the test frequency was $1 \mathrm{~Hz}$. 


\section{Results and Discussion}

\subsection{Microstructure}

Figure 1 shows the SEM images of the Mg-Zn-Y alloys. In Figure 1a, the main phase in sample I is the block phase along the grain boundaries, with some white bright spot-like second phases gathered on the grain boundary. After a $10 \mathrm{~h}$ heating process at $673 \mathrm{~K}$, the grain size in sample II was almost unchanged, and numerous lamellar phases were lined up in the matrix (Figure 1b). For the air-cooling experiment in Figure 1c, due to the slow cooling rate, the grains of the alloy were quite coarse, about $100 \mu \mathrm{m}$, the second phase was networked at the grain boundary, and other second phase structures were almost invisible in the grain. After the heat treatment, the grain size of sample IV also remained unchanged and a small amount of the second phase could be seen in the matrix, but the lamellar phase in the matrix was less obvious than that in sample II.

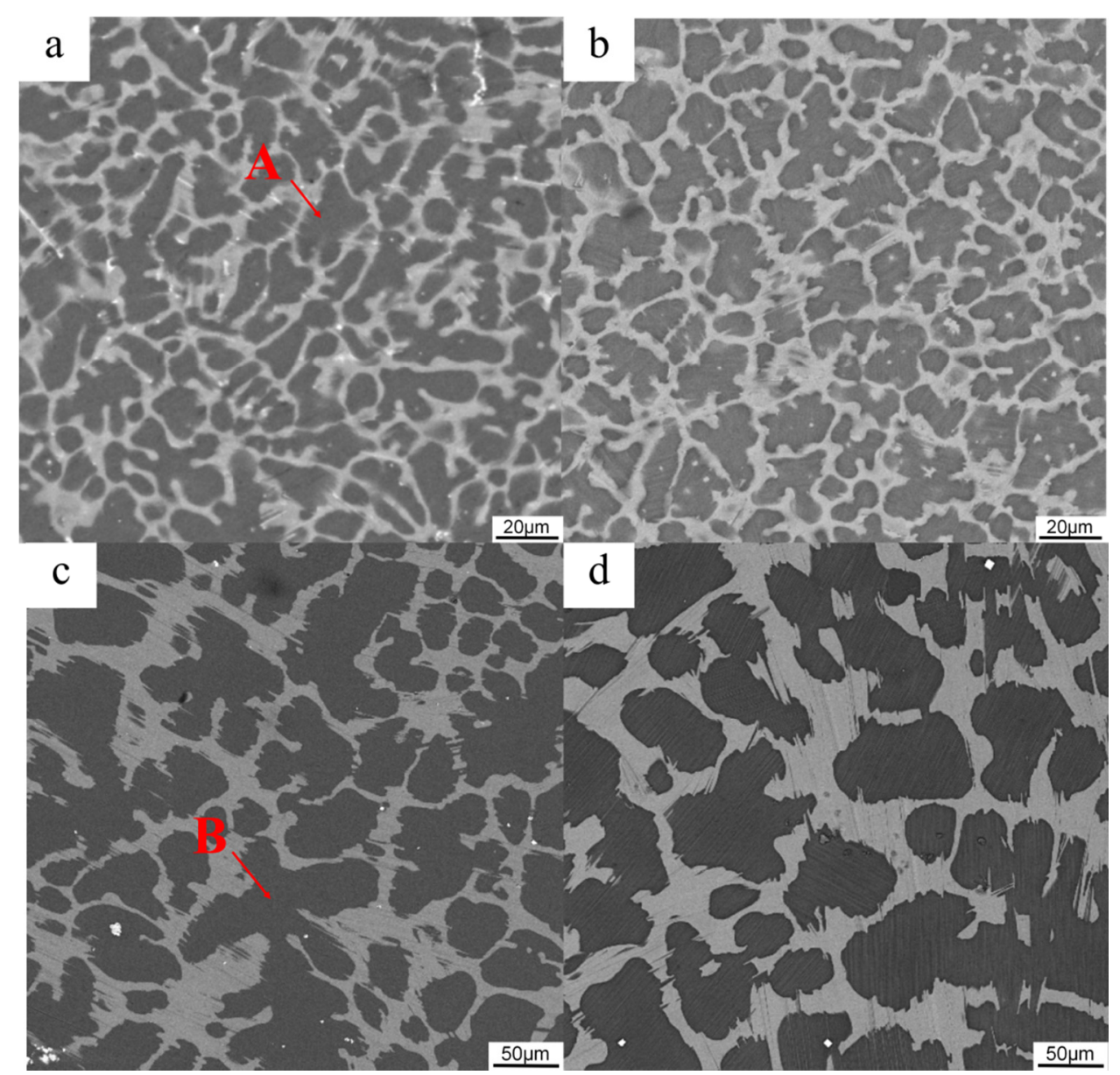

Figure 1. Scanning electron microscope (SEM) images of the Mg-Zn-Y alloys obtained under different conditions: (a) Sample I, (b) sample II, (c) sample III, (d) sample IV.

Figure 2 shows the volume fraction of the block LPSO phase of the alloys, which was about $40 \%$ almost unchanged. The grain sizes of samples I and II were approximately $20 \mu \mathrm{m}$. The microstructure of samples III and IV were also a two-phase structure and the grain size was about $\sim 100 \mu \mathrm{m}$. 


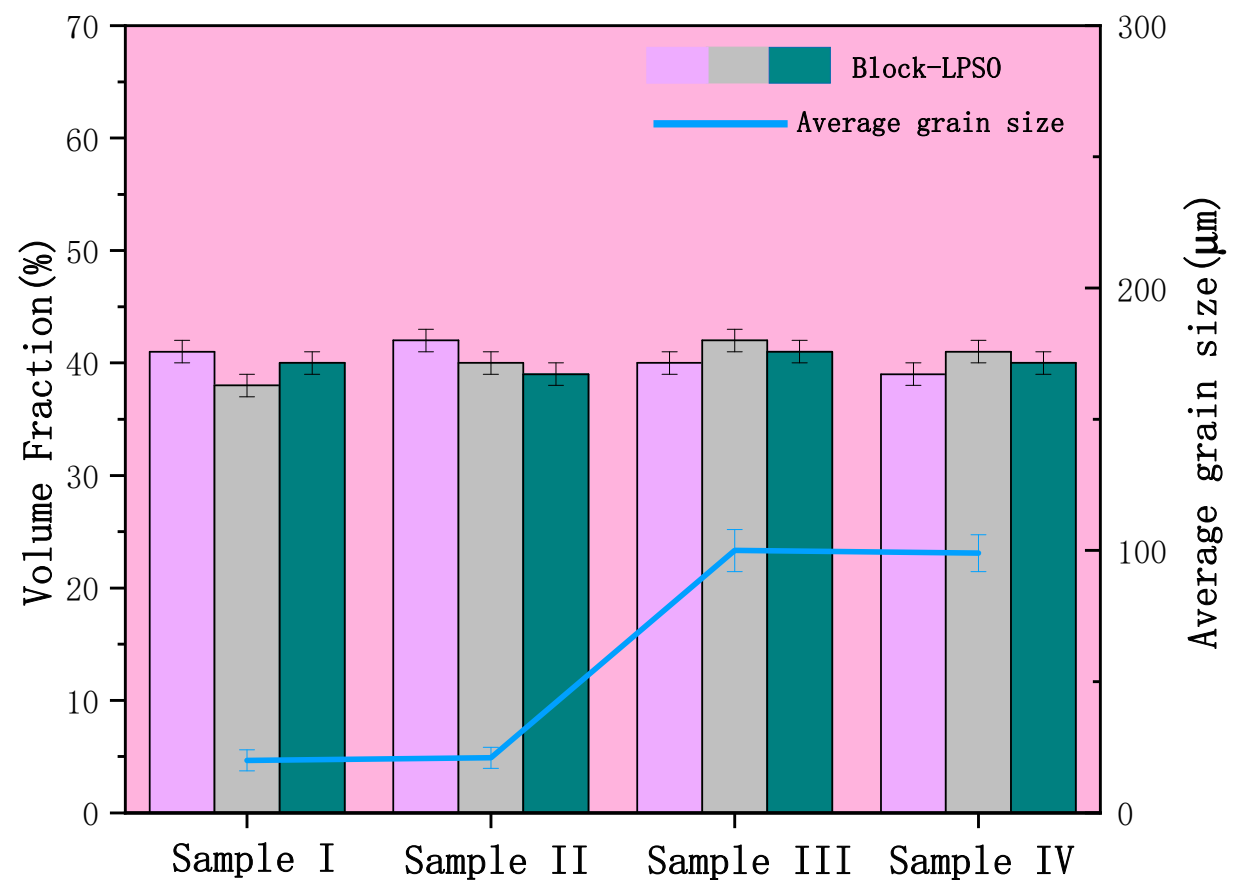

Figure 2. Volume fraction and average grain size of Sample I-Sample IV of Mg-Zn-Y alloys obtained under different conditions.

Figure 3 more clearly shows the lamellar LPSO phase in the $\mathrm{Mg}-\mathrm{Zn}-\mathrm{Y}$ alloy. In Figure $3 a$, the lamellar phase was filled with an entire grain along a particular orientation. Some small white clumps were gathered. The lamellar phases were extremely small to observe clearly. In Figure $3 b$, the lamellar phase was obviously sparse and arranged neatly in the matrix. The EDS quantification results of the secondary phases in all four samples are shown in Table 2. Points A and B were selected in the matrix of the two cast alloys. The quickly cooled sample contained more solid solution atoms than the other samples. The gray block phase (point $C, E$ ) showed an $R E / Z n$ ratio of nearly $4 / 3$ that can be speculated to be the LPSO phase. The region selected for elemental analysis was sufficiently large compared with the lamellar phase. Thus, the result of points D and F was similar to that in the matrix of the two cast alloys. The elements in the crystal changed slightly after the heat treatment. Some studies [21,24] have shown that during annealing, Y and Zn solution atoms are filled orderedly into the stacking faults, then forming a lamellar LPSO phase. Therefore, the lamellar LPSO phase content is related to the content of the solid solution atoms.

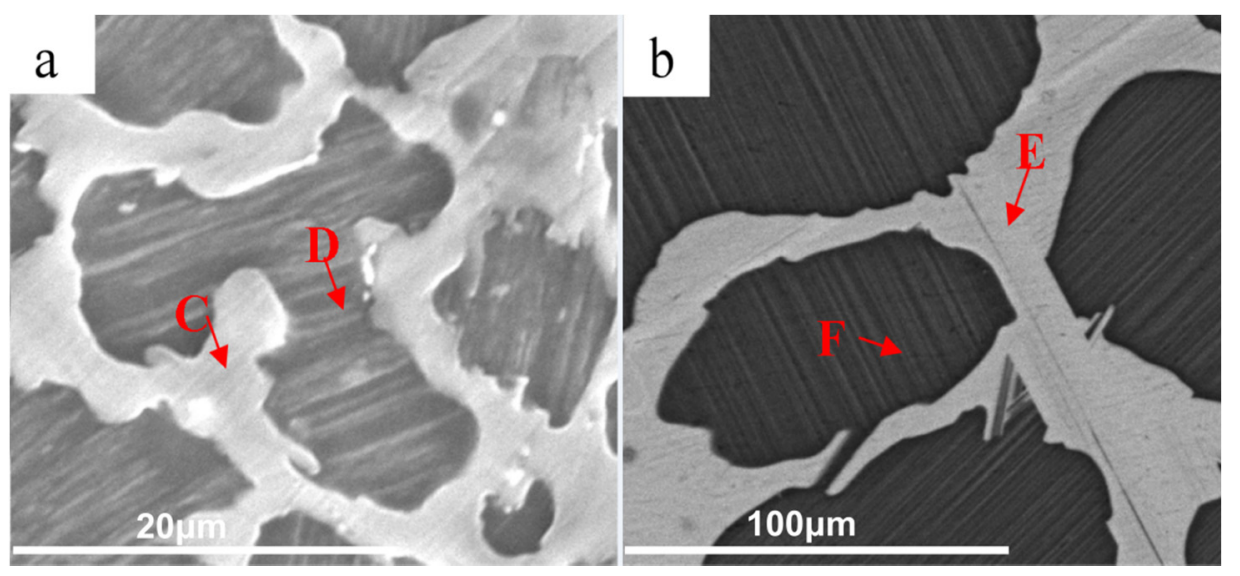

Figure 3. SEM images of the lamellar long period stacking ordered (LPSO) phase: (a) Sample II, (b) sample IV. 
Table 2. Energy dispersive spectroscope (EDS) elemental analysis of the spots specified in Figures 1 and 2.

\begin{tabular}{cccc}
\hline \multirow{2}{*}{ Point } & \multicolumn{3}{c}{ Composition (at.\%) } \\
\cline { 2 - 4 } & $\mathbf{M g}$ & $\mathbf{Z n}$ & $\mathbf{Y}$ \\
\hline A & 98.44 & 0.41 & 1.15 \\
B & 98.91 & 0.34 & 0.75 \\
C & 88.34 & 4.67 & 6.99 \\
D & 97.82 & 0.75 & 1.43 \\
E & 90.24 & 4.12 & 5.64 \\
F & 98.76 & 0.48 & 0.76 \\
\hline
\end{tabular}

Figure 4 shows the bright-field TEM image of the $\mathrm{Mg}-\mathrm{Zn}-\mathrm{Y}$ samples from the direction of [11-20]. It is clear that the gray LPSO phases of sample I showed block shaped morphology in Figure 4a. The SAED pattern showed that the block LPSO phase was an 18R-LPSO phase in cast alloy because it had five and six diffraction spots existing between the central spot and the (0002) $)_{\alpha}$ diffraction spot of $\alpha$-Mg for 18R specially. The gray LPSO phases had a lamer-shaped morphology, as shown in Figure $4 \mathrm{~b}$. The width of the phases had a wide range from several to several hundred nanometers, with different spacing between them. Some LPSO phases showed a spacing of over $200 \mathrm{~nm}$, while some were connected with each other. Correspondingly, the lamellar LPSO phase in sample IV was extremely small and thin. The spacing of the LPSO phases was about tens of nanometers. The diffraction pattern can determine the lamer-shaped phases as a 14H-LPSO structure because within the matrix (Figure 4c) are 14H-LPSO structure with the lattice constant of $a=0.34 \mathrm{~nm}$ and $c=3.58 \mathrm{~nm}$. Figure $4 \mathrm{~d}$ shows that the observed dense 18R lamellar LPSO phase passed the HAADF-STEM. Yamasaki et al. [26] showed that almost no LPSO phase existed in as-cast $\mathrm{Mg}-\mathrm{Gd}-\mathrm{Zn}$ alloys. When the heat treatment temperature was higher than $623 \mathrm{~K}$, there were stacking faults and 14H-LPSO phases in the matrix. As the heat treatment progressed, the $14 \mathrm{H}$ LPSO phase grew slowly. The elemental content also affected the formation of the LPSO phase. The addition of Zn caused the 14H-LPSO phase to precipitate during the high temperature heat treatment. This was due to the fact that $\mathrm{Zn}$ reduced the stacking fault energy $[11,27]$.

\subsection{Properties}

Figure 5 shows the mechanical properties of the four $\mathrm{Mg}-\mathrm{Zn}-\mathrm{Y}$ alloys. Sample I with tiny grains showed the best mechanical properties. Its mechanical property was obviously better than that of sample III with a large grain size. After the heat treatment, the mechanical property of sample II was lower than that of sample I. The mechanical property of sample IV did not decline significantly in comparison with sample III. In general, the quickly cooled samples possessed excellent mechanical properties, which decreased significantly after the heat treatment. The mechanical properties of the air-cooled samples were almost unchanged after the heat treatment.

Figure 6 shows the amplitude-dependent damping performance of the $\mathrm{Mg}_{95.3} \mathrm{Zn}_{2} \mathrm{Y}_{2.7}$ alloys. The damping of the alloys can be divided into two stages. In the low strain stage, the damping of the four samples showed no significant difference. When reaching a high strain region, the damping of samples I and II had been improved to a certain extent, the both $Q^{-1}$ value was about 0.015 at $\varepsilon=10^{-3}$, and the overall performance was still low. In addition, with the increase in strain, the damping value of the air-cooled specimen was greatly increased, and its damping value was significantly higher than that of the water-cooled specimen. After the heat treatment, the damping of sample IV increased greatly when the strain exceeded the critical strain $\left(\varepsilon_{\mathrm{cr}}\right)$. The damping value reached 0.110 at $\varepsilon=10^{-3}$; this value was twice that for sample III. 


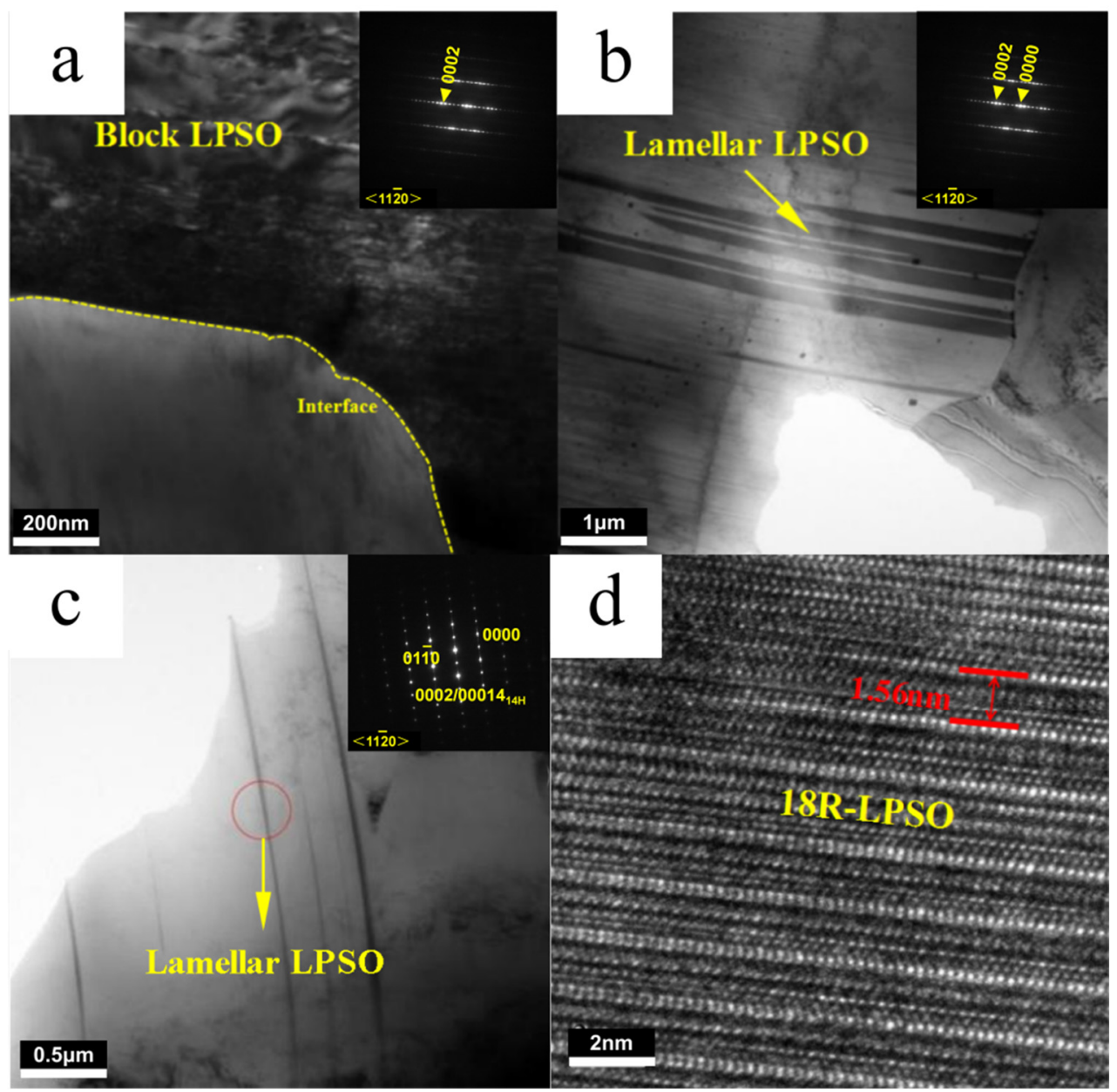

Figure 4. TEM bright-field images and corresponding selected area electron diffraction (SAED) of Mg-Zn-Y alloys: (a) Block LPSO in Sample I; (b) lamellar LPSO phase in Sample III; (c) lamellar LPSO phase in sample IV; (d) the compact lamellar LPSO phase observed passed the HAADF-STEM.

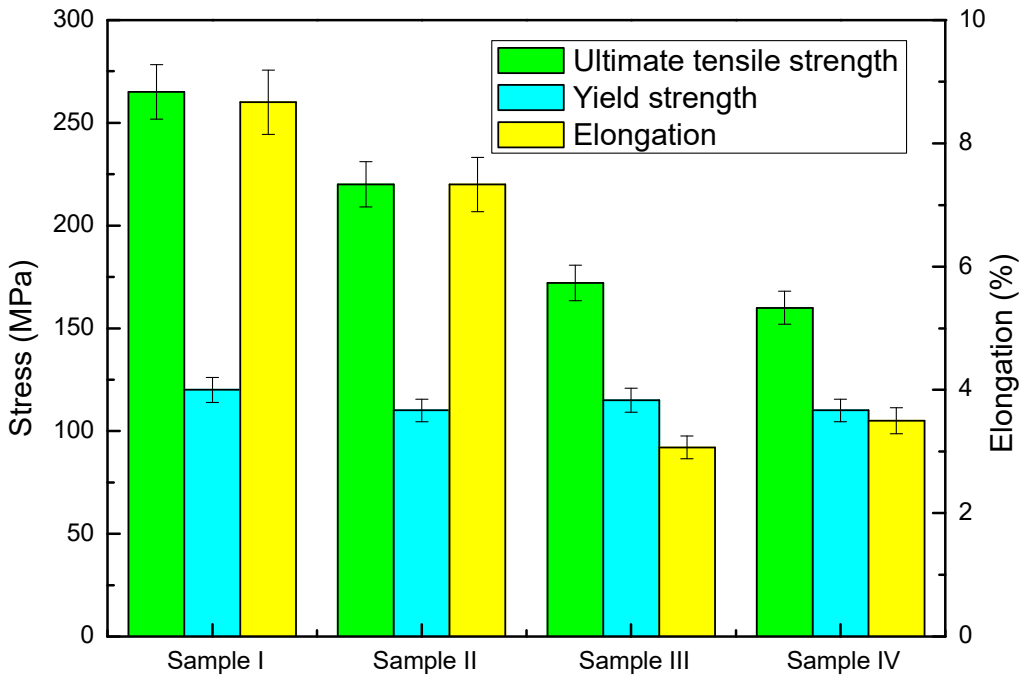

Figure 5. Mechanical properties of the four Mg-Zn-Y alloys. 


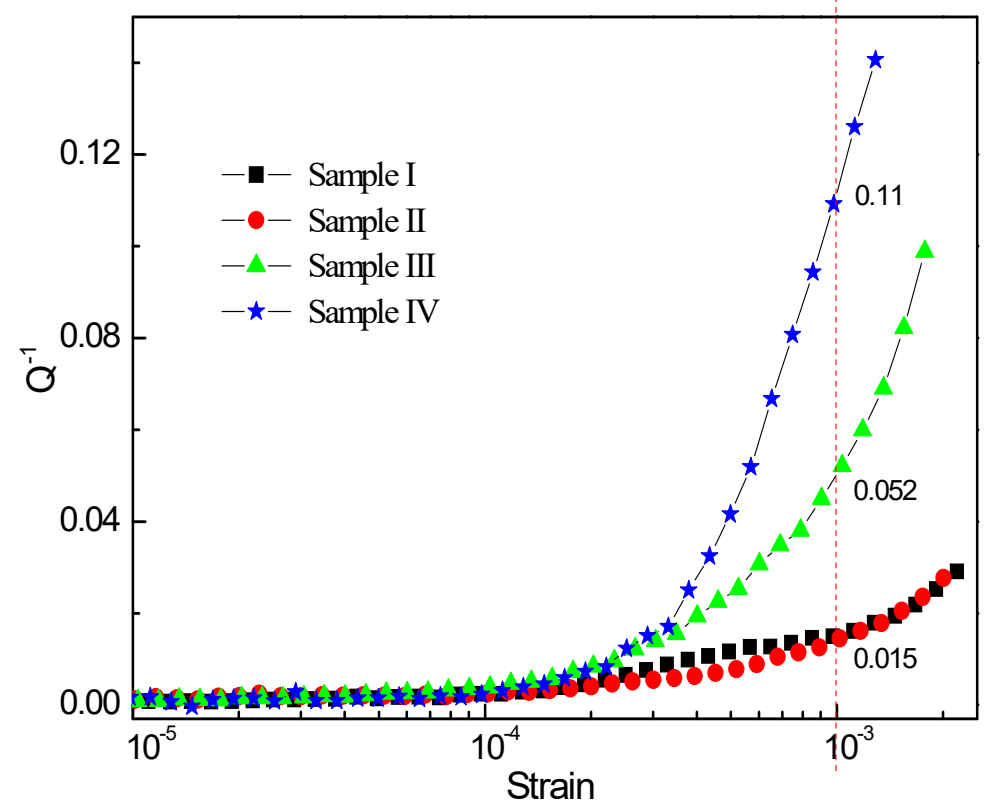

Figure 6. The amplitude-dependent damping performance of the alloys.

This figure shows that the damping of the air-cooled sample was significantly higher than that of the water-cooled sample. In addition, a very interesting phenomenon was found. The same heat treatment process and phase precipitation had significant differences in the performance of those samples, which greatly improved the damping property of the air-cooled samples, but had no effect on the water-cooled samples.

\subsection{Discussion}

The effects of heat treatment processes and precipitation on magnesium alloy damping have been discussed [20], which shows that rod-shaped LPSO phases are favorable for obtaining high-damping and high-strength alloys. The mechanical and damping properties of the samples are summarized in Figure 7. After the heat treatment, the mechanical properties obviously reduced in fine grain samples, although the damping was almost unchanged. In large grain samples, the damping increased significantly with the appearance of lamellar LPSO, and the mechanical properties were not significantly reduced. Sample IV had an ultimate tensile strength of $160 \mathrm{MPa}$, yield strength of $110 \mathrm{MPa}$, and damping capacity of 0.110 at $\varepsilon=10^{-3}$. Compared to the alloy containing the rod-shape LPSO phase [20], which is represented by pre-study in Figure 7, the tensile strength was reduced from $210 \mathrm{MPa}$ to $160 \mathrm{MPa}$, but the yield strength was increased from $100 \mathrm{MPa}$ to $110 \mathrm{MPa}$, and the damping value $Q^{-1}$ was increased from 0.048 to 0.11 . The result shows that sample IV sacrificed part mechanics for higher damping, but also presented excellent comprehensive performance as a damping alloy.

Notably, the formation of a lamellar phase results in an obvious difference in the damping properties of the alloys with the same composition, but different grain sizes. The damping capacity of $\mathrm{Mg}$ alloys is known to be caused by dislocation motion, so this phenomenon can be explained by the Granato-Lücke (G-L) theory $[28,29]$. According to the G-L model, dislocations in the alloy are pinned by defects such as precipitates, solute atoms, and vacancies. In the vibration process, the dislocation damping capacity can be divided into two stages

$$
Q^{-1}(\varepsilon)=Q_{\mathrm{o}}^{-1}+Q_{\mathrm{H}}^{-1}(\varepsilon)
$$

where $Q_{\mathrm{o}}{ }^{-1}$ is the strain independent damping. In this part, dislocations only vibrate between pinning points causing energy consumption with small stresses. When the strain amplitude exceeds the critical strain $\left(\varepsilon_{\mathrm{cr}}\right)$, dislocations in the vibration break away from the weak pinning point, but are still bound by the strong pinning point, and damping 
$\left(Q_{\mathrm{H}}{ }^{-1}\right)$ is obtained in the process. In this process, damping behavior can be expressed by the following formula:

$$
\begin{gathered}
\mathrm{Q}_{\mathrm{H}}^{-1}=\left(C_{1} / \varepsilon\right) \exp \left(-C_{2} / \varepsilon\right) \\
C_{1}=\left(\rho F_{\mathrm{B}} L_{\mathrm{N}}{ }^{3}\right) /\left(6 b E L_{C}{ }^{2}\right) \\
C_{2}=F_{\mathrm{B}} / b E L_{\mathrm{C}}
\end{gathered}
$$

In the formula, $\rho$ is expressed as mobile dislocation density; $L_{N}$ represents the average length between adjacent strong pinning points; $L_{C}$ represents the average length between the adjacent weak pinning point, and the binding force between the dislocation and the weak pinning point can be represented by $F_{\mathrm{B}} ; E$ is the elastic modulus; and $b$ is the dislocation Burt vector. According to the above formula, it can be known that $C_{1}$ is mainly related to the dislocation density $\rho$, the average dislocation segment length between strong pinning points $L_{N}$, and the average distance between weak pinning points $L_{C}$. $C_{2}$ reflects inversely proportional to the average distance $L_{C}$ between weak pinning points.

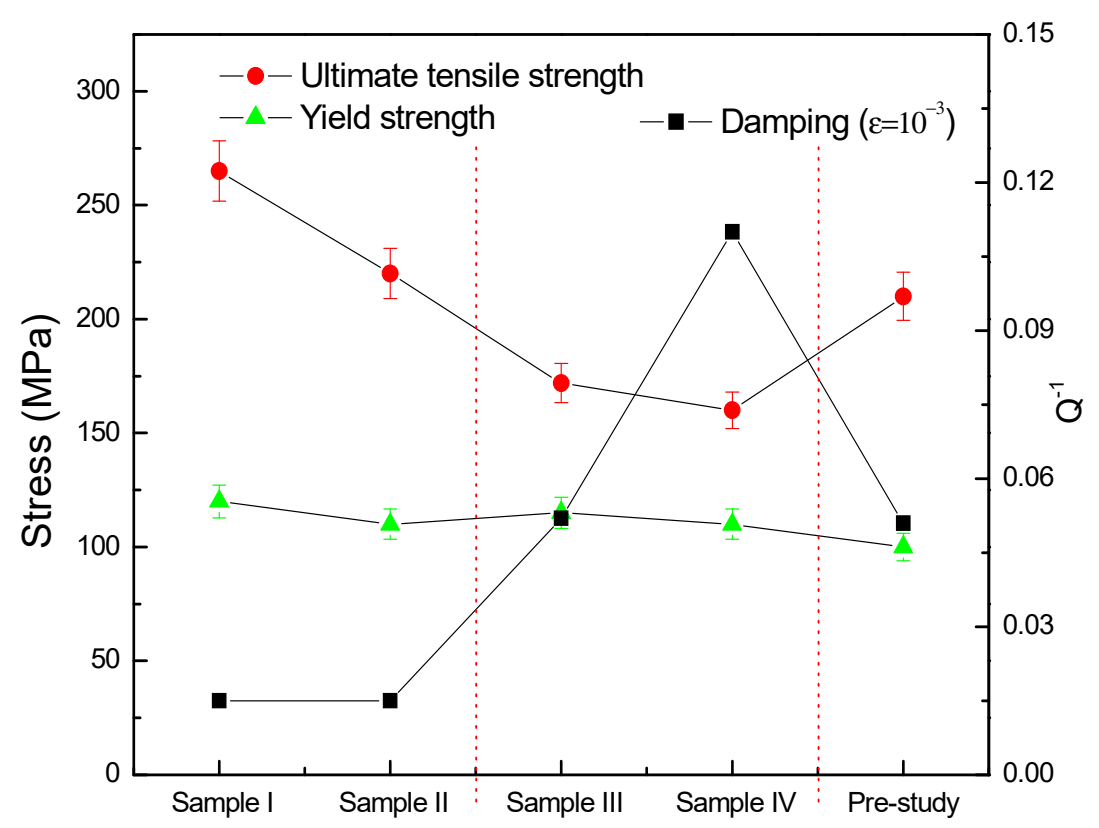

Figure 7. Comprehensive comparison of the damping and mechanical properties of the $\mathrm{Mg}_{95.3} \mathrm{Zn}_{2} \mathrm{Y}_{2.7}$ alloys.

In Mg alloys, solid solution atoms act as a strong pinning point in the damping behavior. Thus, excessive solid solution atoms will reduce the $L_{N}$ value. This condition does not benefit the damping capacity. In this work, the quickly cooled samples with a large number of solid solution atoms had a relatively low damping capacity at the high-strain amplitude region. Grain boundaries also acted as strong pinning points. Fine grains can improve the mechanical properties according to Hall-Petch relationships; however, they can also reduce the damping capacities to some extent. Sugimoto [30] concluded that a high-damping alloy should have limited solute atoms and appropriate grain size. The solid-solution atoms in the damping magnesium alloy were as small as possible, and the grain size was larger than $10 \mu \mathrm{m}$, and the microstructure was dendritic or spherical.

Zhu [31] researched the $18 \mathrm{R}$ and $14 \mathrm{H}$ long-period stacking ordered structures in $\mathrm{Mg}$ $\mathrm{Y}-\mathrm{Zn}$ alloys. Egusa [32] researched the structure of long period stacking/order $\mathrm{Mg}-\mathrm{Zn}-\mathrm{RE}$ phases with extended non-stoichiometry ranges. After heat treatment at $673 \mathrm{~K}$ for 10 $\mathrm{h}$, a layered 14H-LPSO phase was found in the alloy. The current research showed that when the Mg-RE-Zn alloy is heat-treated at $673 \mathrm{~K}$, the RE and Zn elements will fill the stacking faults in the matrix and form the LPSO structure. The transformation process is: $\alpha-\mathrm{Mg} \rightarrow \mathrm{SF} \rightarrow 14 \mathrm{H}-\mathrm{LPSO}$ [33]. The formation of lamellar LPSO phases can decrease the content of solid solution atoms, which act as a strong pinning point in the damping 
behavior. Nevertheless, in sample II, the distance between the adjacent LPSO layers is highly compact. The precipitation phase will still reduce the dislocation damping. In sample IV, the distance between two lamellar LPSO phases was adequate. Thus, the $L_{N}$ value will not decline and hinder the dislocation motion in the matrix. As a result of the decrease in the number of solid solution atoms in the matrix, the damping capacity is improved.

As we know, a high damping capacity in a Mg alloy needs the dislocation vibration to dissipate energy. However, traditional reinforcement materials need to hinder dislocation movement. Therefore, it is currently difficult to obtain magnesium alloys with high strength and high strength properties. Schaller [17] suggested two-phase composites, each of which plays a specific role of damping or strengthening. Chino [34] suggested that in the LPSO structure, the high internal energy stored due to lattice distortions and changes in electronic structure resulted in the LPSO phase having higher elastic modulus, hardness, and maintaining high ductility. Garcés [35] found that under the action of alternating stress, the force behavior of the $\mathrm{Mg}-\mathrm{Y}-\mathrm{Zn}$ alloy containing the LPSO phase behaves like a metal matrix composite, and the Mg matrix transfers part of its load to the LPSO phase. Therefore, in sample IV, the block LPSO phases on the grain boundary acted like a solid framework. The lamellar LPSO phases resembled a support structure, and the Mg matrix with limited solute atoms was the high damping filler, as shown in Figure 8. Moreover, there was a good bonding interface between the second phase and the alloy matrix. The LPSO phase had a considerable influence on mechanical properties, and the Mg matrix contributed greatly to damping. Therefore, a two-phase alloy can obtain high damping ability and good mechanical property.

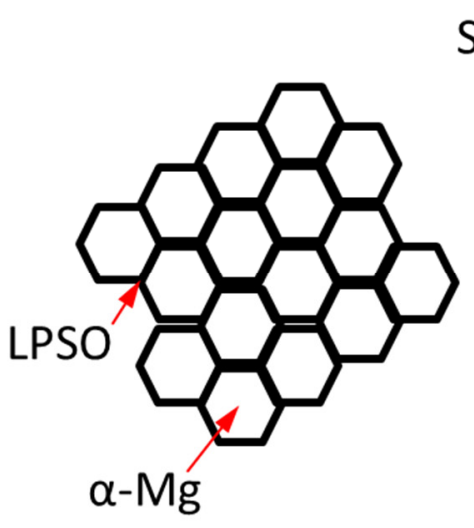

Step 1

Step 2
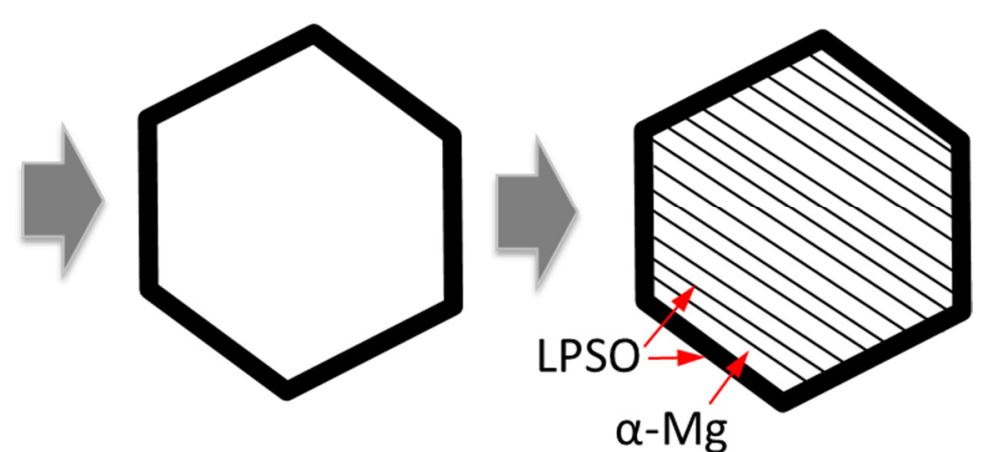

Figure 8. Simple graph of the microstructure transformation process in this work.

\section{Conclusions}

In this work, the damping capacities of $\mathrm{Mg}-\mathrm{Zn}-\mathrm{Y}$-based alloys were simultaneously improved by obtaining the right amount of lamellar 14H-LPSO phase. After a $10 \mathrm{~h}$ heat treatment at $673 \mathrm{~K}$, the lamellar $14 \mathrm{H}-\mathrm{LPSO}$ phase was precipitated in the $\mathrm{Mg}_{95.3} \mathrm{Zn}_{2} \mathrm{Y}_{2.7}$ alloy, and the density of the precipitated phase is related to the required solid solution atom content. The density of the lamellar LPSO phase had an obvious effect on the damping of the magnesium alloy. The damping capacity could not be improved by obtaining the compact LPSO lamellar phase, but sparse lamellar phases can improve the damping capacity of alloys without significantly reducing mechanical properties, particularly yield strength. The $\mathrm{Mg}_{95.3} \mathrm{Zn}_{2} \mathrm{Y}_{2.7}$ alloys with lamellar LPSO phases and $\sim 100 \mu \mathrm{m}$ grain size exhibited a yield strength of $110 \mathrm{MPa}$ and damping capacity of 0.110 at $\varepsilon=10^{-3}$.

Author Contributions: R.L. and H.H. designed the experiments; K.J., K.L., K.Y. and Y.Z. conducted the experiments and collected the data; R.L. analyzed the data; R.L. wrote the paper. All authors have read and agreed to the published version of the manuscript. 
Funding: This study was funded by the National Natural Science Foundation of China (Nos. 51801189, 51804279); The Science and Technology Major Project of Shanxi Province (No. 20191102008. 20191102007); The Scientific and Technological Innovation Programs of Higher Education Institutions in Shanxi (No. 2019L0523); The North University of China Youth Academic Leader Project(No. 11045505).

Informed Consent Statement: Obtain informed consent from all subjects participating in the study.

Data Availability Statement: The data used to support the findings of this study are available from the corresponding authors upon reasonable request.

Conflicts of Interest: The authors declare that they have no conflicts of interest.

\section{References}

1. Luo, A.A. Magnesium casting technology for structural applications. J. Magnes. Alloys. 2013, 1, 2-22. [CrossRef]

2. Jiang, H.J.; Liu, C.Y.; Zhang, B.; Xue, P.; Ma, Z.Y.; Luo, K.; Ma, M.Z.; Liu, R.P. Simultaneously improving mechanical properties and damping capacity of Al-Mg-Si alloy through friction stir processing. Mater. Charact. 2017, 131, 425-430. [CrossRef]

3. Wan, D.Q. Near spherical $\alpha-\mathrm{Mg}$ dendrite morphology and high damping of low-temperature casting Mg-1wt.\%Ca alloy. Mater. Charact. 2011, 62, 8-11.

4. Yan, B.S.; Dong, X.P.; Ma, R.; Chen, S.Q.; Pan, Z.; Ling, H.J. Effects of heat treatment on microstructure, mechanical properties and damping capacity of Mg-Zn-Y-Zr alloy. Mater. Sci. Eng. A 2014, 594, 168-177. [CrossRef]

5. Wan, D.Q.; Wang, H.B.; Ye, S.T.; Hu, Y.L.; Li, L.L. The damping and mechanical properties of magnesium alloys balanced by aluminum addition. J. Alloys Compd. 2019, 782, 421-426. [CrossRef]

6. Niu, R.L.; Yan, F.G.; Duan, D.P.; Yang, X.M. Effect of yttrium addition on microstructures, damping properties and mechanical properties of as-cast Mg-based ternary alloys. J. Alloys Compd. 2019, 785, 1270-1278. [CrossRef]

7. Cheng, P.; Zhao, Y.H.; Lu, R.P.; Hou, H.; Bu, Z.Q.; Yan, F. Effect of Ti addition on the microstructure and mechanical properties of cast Mg-Gd-Y-Zn alloys. Mater. Sci. Eng. A 2017, 708, 482-491. [CrossRef]

8. Cheng, P.; Zhao, Y.H.; Lu, R.P.; Hou, H. Effect of the morphology of long-period stacking ordered phase on mechanical properties and corrosion behavior of cast Mg-Zn-Y-Ti alloy. J. Alloys Compd. 2018, 764, 226-238. [CrossRef]

9. Ding, Z.B.; Zhao, Y.H.; Lu, R.P.; Pei, H.X.; Hou, H. Microstructure evolution and mechanical properties of Mg-10Gd-3Y-xZn-0.6Zr alloys. J. Mater. Res. 2018, 33, 1797-1805. [CrossRef]

10. Kawamura, Y.; Hayashi, K.; Inoue, A.; Masumoto, T. Rapidly Solidified Powder Metallurgy MgZn $\mathrm{Y}_{2} \mathrm{Alloys}_{\mathrm{N}}$ with Excellent Tensile Yield Strength above $600 \mathrm{MPa}$. Mater. Trans. 2001, 42, 1172-1176. [CrossRef]

11. Itoi, T.; Seimiya, T.; Kawamura, Y.; Hirohashi, M. Long period stacking structures observed in Mg97Zn1Y2 alloy. Scripta Mater. 2004, 51, 107-111. [CrossRef]

12. Wang, J.F.; Gao, S.; Song, P.F.; Huang, X.F.; Shi, Z.Z.; Pan, F.S. Effects of phase composition on the mechanical properties and damping capacities of as-extruded Mg-Zn-Y-Zr alloys. J. Alloys. Compd. 2011, 509, 8567-8572. [CrossRef]

13. Wang, J.F.; Lu, R.P.; Wei, W.W.; Huang, X.F.; Pan, F.S. Effect of long period stacking ordered structure on the damping capacities of Mg-Ni-Y alloys. J. Alloys Compd. 2012, 537, 1-5. [CrossRef]

14. Qin, D.Z.; Wang, J.F.; Chen, Y.L.; Lu, R.P.; Pan, F.S. Effect of long period stacking ordered structure on the damping capacities of Mg-Ni-Y alloys. Mater. Sci. Eng. A 2015, 624, 9-13. [CrossRef]

15. Tang, Y.X.; Li, B.; Tang, H.X.; Xu, Y.C.; Gao, Y.P.; Wang, L.H.; Guan, J.Y. Effect of long period stacking ordered structure on mechanical and damping properties of as-cast Mg-Zn-Y-Zr alloy. Mater. Sci. Eng. A 2015, 640, 287-294. [CrossRef]

16. Yuan, J.W.; Li, T.; Zhang, K.; Li, M.; Li, X.G.; Li, Y.J.; Ma, M.L.; Shi, G.L. Effect of Zn content on the microstructures, mechanical properties, and damping capacities of Mg-7Gd-3Y-1Nd-0.5Zr based alloys. J. Alloys Compd. 2019, 773, 919-926. [CrossRef]

17. Schaller, R. Metal matrix composites, a smart choice for high damping materials. J. Alloys Compd. 2003, 355, 131-135. [CrossRef]

18. Ren, L.B.; Quan, G.F.; Xu, Y.G.; Yin, D.D.; Lu, J.W.; Dang, J.T. Effect of heat treatment and pre-deformation on damping capacity of cast Mg-Y binary alloys. J. Alloys Compd. 2017, 699, 976-982. [CrossRef]

19. González-Martínez, R.; Göken, J.; Letzig, D.; Steinhoff, K.; Kainer, K.U. Influence of aging on damping of the magnesiumaluminium-zinc series. J. Alloys Compd. 2007, 437, 127-132. [CrossRef]

20. Lu, R.P.; Wang, J.F.; Chen, Y.L.; Qin, D.Z.; Yang, W.X.; Wu, Z.S. Effects of heat treatment on the morphology of long-period stacking ordered phase, the corresponding damping capacities and mechanical properties of Mg-Zn-Y alloys. J. Alloys Compd. 2015, 639, 541-546. [CrossRef]

21. Yamasaki, M.; Anan, T.; Yoshimoto, S.; Kawamura, Y. Mechanical properties of warm-extruded Mg-Zn-Gd alloy with coherent $14 \mathrm{H}$ long periodic stacking ordered structure precipitate. Scripta Mater. 2005, 53, 799-803. [CrossRef]

22. Oñorbe, E.; Garcés, G.; Pérez, P.; Cabezas, S.; Klaus, M.; Genzel, C.; Frutos, E.; Adeva, P. The evolution of internal strain in Mg-Y-Zn alloys with a long period stacking ordered structure. Scripta Mater. 2011, 65, 719-722. [CrossRef]

23. Shi, X.; Long, Y.; Zhang, H.; Chen, L.; Zhou, Y.; Yu, X.; Yu, X.; Cai, L.; Leng, Z. Role of LPSO Phase in Crack Propagation Behavior of an As-Cast Mg-Y-Zn Alloy Subjected to Dynamic Loadings. Materials 2019, 12, 498. [CrossRef] [PubMed]

24. Gröbner, J.; Kozlov, A.; Fang, X.Y.; Geng, J.; Nie, J.F.; Schmid-Fetzer, R. Phase equilibria and transformations in ternary Mg-rich Mg-Y-Zn alloys. Acta Mater. 2012, 60, 5948-5962. [CrossRef] 
25. Huang, S.; Wang, J.F.; Hou, F.; Huang, X.H.; Pan, F.S. Effect of Gd and Y contents on the microstructural evolution of long period stacking ordered phase and the corresponding mechanical properties in Mg-Gd-Y-Zn-Mn alloys. Mater. Sci. Eng. A 2014, 612, 363-370. [CrossRef]

26. Yamasaki, M.; Sasaki, M.; Nishijima, M.; Hiraga, K.; Kawamura, Y. Formation of $14 \mathrm{H}$ long period stacking ordered structure and profuse stacking faults in Mg-Zn-Gd alloys during isothermal aging at high temperature. Acta Mater. 2007, 55, 6798-6805. [CrossRef]

27. Yoshimoto, S.; Yamasaki, M.; Kawamura, Y. Microstructure and Mechanical Properties of Extruded Mg-Zn-Y Alloys with 14H Long Period Ordered Structure. Mater. Trans. 2006, 47, 959. [CrossRef]

28. Granato, K.L. Theory of Mechanical Damping Due to Dislocations. J. Appl. Phys. 1956, 27, 583. [CrossRef]

29. Granato, K.L. Application of Dislocation Theory to Internal Friction Phenomena at High Frequencies. J. Appl. Phys. 1956, 27, 789. [CrossRef]

30. Sugimoto, K.; Niiya, K.; Okamoto, T.; Kishitake, K. A Study of Damping Capacity in Magnesium Alloys. Trans. JIM 1977, 18, 277. [CrossRef]

31. Zhu, Y.M.; Morton, A.J.; Nie, J.F. The $18 \mathrm{R}$ and $14 \mathrm{H}$ long-period stacking ordered structures in Mg-Y-Zn alloys. Acta Mater. 2010, 58, 2936-2947. [CrossRef]

32. Egusa, D.; Abe, E. The structure of long period stacking/order Mg-Zn-RE phases with extended non-stoichiometry ranges. Acta Mater. 2012, 60, 166-178. [CrossRef]

33. Gao, X.; Nie, J.F. Enhanced precipitation-hardening in Mg-Gd alloys containing Ag and Zn. Scripta Mater. 2008, 58, 619-622. [CrossRef]

34. Chino, M.; Mabuchi, S.H.; Iwasaki, H.; Yamamoto, A.; Tsubakino, H. Novel equilibrium two phase Mg alloy with the long-period ordered structure. Scripta Mater. 2004, 51, 711-714. [CrossRef]

35. Garcésa, G.; Oñorbea, E.; Dobesb, F.; Péreza, P.; Antoranzc, J.M.; Adevaa, P. Effect of microstructure on creep behaviour of cast $\mathrm{Mg}_{97} \mathrm{Y}_{2} \mathrm{Zn}_{1}$ (at.\%) alloy. Mater. Sci. Eng. A 2012, 539, 48-55. [CrossRef] 